\begin{tabular}{ccc}
\hline International Journal of Engineering \& Technology, $7(2.1)(2018) 84-86$ \\
SPC \\
Website $:$ ww.sciencepubco.com/index.php/IJET \\
Research Paper
\end{tabular}

\title{
Review on foundation practices for expansive soils, special emphasis on granular anchor pile foundation
}

\author{
Munnangi RaviTeja ${ }^{1^{*}}$, N.R Krishna Murthy ${ }^{2}$ \\ ${ }^{1}$ Postgraduate student, V.R Siddhartha Engineering College Vijayawada \\ ${ }^{2}$ Professor V.R Siddhartha Engineering College Vijayawada \\ E-mail: munnangiraviteja@gmail.com
}

\begin{abstract}
Mostly the lightly loaded structures founded in expansive soils develop cracks owing to alternate shrinkage and swelling as the weight of superstructure cannot counteract the swelling pressure. Hence the cost of foundation to be laid in these soils must be suitable proportions to low cost of structure. This paper presents a critical review on emphasis on granular anchor pile foundation and other the foundation practices for expansive soil.
\end{abstract}

Keywords: Expansive Soil, Foundation, Granular Anchor Pile

\section{Introduction}

The expansive soil which have tendency to increase in volume when water is available and decrease in volume if water is removed. Expansive soils swell on inhibition of water during the monsoon, reduce in density and becomes slushy, but in dry seasons shrink because of evaporation of water and becomes hard due to amplify in density. The volumetric distortion in these dirts ascribed to regular varieties in the ground water profile bringing about changes in dampness content. Amid summer polygonal shrinkage breaks shows up close to the surface, reaching out to a profound of around $2 \mathrm{~m}$, demonstrating a high potential for extension and withdrawal. In the world most of countries are facing problems with these soils are Australia, Africa, Egypt, Europe, Canada, China, India, Israel, Unite States. Swelling soils of India are commonly known as black cotton soils, because of their color and their suitability for growing cotton. Expansive soil, commonly known as black cotton soil, is one of the major regional deposits in India, covering an area of about 3.0 lakh sq.km and $20 \%$ of area covered with these soils. The entire stratum of expansive soil in the field may not be active. Rama Swamy (1990) observed that in certain areas the depth of active zone might extend beyond $3.5 \mathrm{~m}$ also. The maximum swelling pressure may be high as $1915 \mathrm{kN} / \mathrm{m}^{2}$

\section{Identification of Expansive soils}

\subsection{Based on mineralogical composition}

The degree of volume changes experienced by an expansive soil depends on its mineralogical composition. The three basic groups of clay minerals are montmorillonite, illite, kaolinite .The presence of montmorillonite which has an expanding lattice contributes most to swelling while that of illite contributes a little less, kaolinite other hand are non expansive.

\subsection{Identification from Index properties}

In India, black cotton soils have liquid limit values ranging from 50 to $100 \%$, plasticity index ranging from 20 to $65 \%$ and shrinkage limit from 9 to $14 \%$. Skemtons (1953) explained the expansiveness based on the activity, Holtz and Gibbs (1956) developed the free swell test for determination of swell potential of a soil. And Seed et al gave expression for the swell potential in terms of activity and clay content. Mohan (1977) gave degree of expansion based on liquid limit and plasticity index, shrinkage index. By soil suction properties can be characterizes an expansive soil indicates the affinity a soil has for water(Snethen 1979). By placement conditions swelling characteristics can be related.

\subsection{Direct measurements of swelling pressure}

By method of different surcharges, constant volume method, swell consolidation method swelling pressure can be directly measured.

\section{Existing Foundation Practices For Expansive Soils}

\subsection{Avoiding expansive material}

Avoiding the expansive soil favour of safer foundation soil is not an economically viable proposition in most of the situations.

\subsection{Alternations for minimizing heave}

Mechanical alternations :- It includes excavation soil and replacement with non expansive material, where the depth of active zone is small and where a suitable replacement material is available 
Sand cushion method:-In this method the entire depth of the expansive soil stratum or a part there of may be removed and replaced with a sand cushion, compacted to the desired density and thickness. Swelling pressure varies inversely as the thickness of the sand layer and directly as its density. Therefore, generally sand cushions are formed in their loosest possible state without, however, violating the bearing capacity criterion. The basic advantage of the sand cushion method is its ability to adapt itself to volume changes in the soil. However, the sand cushion method has several limitations particularly when it is adopted in deep strata. Most of the foundation engineers often suggest some arbitrary thickness for the sand pad without thought to the profundity of the zone of potential volume change which itself is hard to decide. The high penetrability of sand makes conditions helpful for simple entrance and amassing of water from surface spillover.

Cohesive non swelling (CNS) layer :- In this method about top $1 \mathrm{~m}$ to $1.2 \mathrm{~m}$ of expansive layer is removed and replaced by cohesive non swelling soil layer. Saturation of expansive soil forces are developed up to a depth of 1 to $1.2 \mathrm{~m}$ and counteract heave. The disadvantage of this system is it not easy to get a material which conforms to the specifications. Moorum is an example of CNS material.

Chemical alternation :- This involves addition of chemicals to expansive clay to reduce by altering the nature of clay minerals of chemicals tried, lime is the most effective and economical additive. This technique has limitation that top few layers of the soil are modified lime slurry injection lime soil columns were also tried to stabilize expansive clays in situ that diffusion of lime is effective upto a radial distance of about 3 times the diameter of lime - soil columns. Some investigators have tried and succeeded in minimizing the swelling of expansive soil using chemicals like calcium chloride $\left(\mathrm{CaCl}_{2}\right)$, calcium sulfate ( $\mathrm{CaSO} 4)$, potassium chloride $(\mathrm{Kcl})$, aluminum chloride $\left(\mathrm{AlCl}_{3}\right)$, etc.

\subsection{Adopting special foundation techniques}

Pad foundations - pad foundations are a series of individual footing pads placed on the upper soil and spanned by grade beams.

Drilled piers :- piers of little diameter but of significant length are drilled into expansive soils up to the zone unaltered by moisture content. Both the end bearing resistance and skin resistance increases with depth at the rate of about $10 \%$ per meter.

Belled piers :- These are the piers with enlarged base adopted to increase the carrying capacity.

Friction piers :- Where the bed rock is very deep and upper layers of the soil are expansive, friction piers can be used. the drawback is that soft soil not be encountered within the length of pier.

Under reamed piles :- Under-reamed exhausted heaps were presented in India by Central Building Research Institute (C.B.R.I), Roorkee. In India, at around $3.5 \mathrm{~m}$ beneath the ground, developments are insignificant and if establishments are secured at that profundity, they will stay stable. In light of this guideline, under-reamed heaps were received for establishments in far reaching soils in India. The globules are given by and large in the latent zone where adequate jetty is accessible. The measurement of the stem of the under-reamed heap ranges from 20$50 \mathrm{cms}$ and the distance across of the knob is regularly $2 \frac{1}{2} 2$ times the width of the stem. The dispersing of the knobs, on account of multi under-reamed heap, ought not surpass $1 \frac{1 / 2}{2}$ times the globule measurement. The Bureau of Indian Standards has additionally brought a code IS 2911: Part III-1980 on under-reamed heaps. The arrangement may not be practical especially for softly stacked structures.

\section{Granular Pile-Anchor Foundation (GPAF) System}

Granular piles are effective in improving the bearing capacity and reducing the settlement of weak soils. A mere granular pile, cannot be effective in expansive clay beds. As it is a particulate medium, it cannot counteract the tensile uplift force caused by swelling soils on foundations. However, when a granular pile is modified into a granular pile-anchor by providing an anchor, the pile becomes tension-resistant and can counteract tensile uplift force.

Babushanker et al (1980) have watched that under-reamed heap establishments experience the ill effects of the trouble of both arrangement whereupon the entire system of tying down depends. Phanikumar et al (1996) felt that the cost of underreamed heap establishment is more than reasonable for masslodging especially for economically weaker segments and furthermore for other light structures where the cost of structure itself is low. In this method the establishment is secured at the last a granular heap to gentle steel plate with the assistance of a mellow steel dowel. This is known as a granular heap stay. As the granular heap is a particulate medium, it can't avoid the tractable elevate compel on the establishment, and in that capacity should be changed into a heap grapple by the above system. As the broad soil ingests water, it swells and inspires the establishment. Be that as it may, a gigantic protection from elevate is activated along the tube shaped pile- soil interface as a result of the shear parameters of the Pile-soil Interface, and the shear protection increased by the parallel swelling weight. In the field has demonstrated that hurl of the expansive clay bed reduces and its strength increases, the compressive strength of GPAreinforced expansive clay bed increases and the uplift resistance of the GPA increases. The forces acting on it are depicted in Fig. 1 It can be seen from Fig. 1 that the vertical uplift force $\mathrm{Pu}$ acting on the base of the foundation due to swelling pressure is given by

$P_{u}=p_{s}\left(D_{f}^{2}-D_{p}^{2}\right) \pi / 4$

Where $D_{\mathrm{f}}$ is the diameter of the foundation,

$\mathrm{D}_{\mathrm{gp}}$ is the diameter of GPA, $\mathrm{p}_{\mathrm{s}}$ is the swelling pressure,

$\mathrm{P}_{\mathrm{r}}=\left[\pi \mathrm{D}_{\mathrm{gp}} \mathrm{L}_{\mathrm{gp}}\left(\mathrm{C}^{\prime}+\mathrm{K} \tan \emptyset^{\prime}+\mathrm{k}_{\mathrm{s}} \mathrm{p}_{\mathrm{s}} \tan \emptyset{ }^{\prime}\right)+\mathrm{W}_{\mathrm{gp}}\right]$

where $\mathrm{Lgp}_{\mathrm{g}}$ is the length of GPA

C',Ǿ are the shear parameters of pile-soil interface,

$\mathrm{K}$ is the earth pressure coefficient, $\mathrm{K}_{\mathrm{s}}$ is the coefficient of lateral swell pressure,

$\sigma_{\mathrm{vo}}$ is the average effective vertical overburden pressure,

$\mathrm{W}_{\mathrm{gp}}$ is the weight of granular pile anchor.

\section{Field test programs}

A full-scale field study was conducted $(1,2)$ to assess the swelling behavior, compression and pull-out resistance of GPAs embedded in expansive clay beds.

\subsection{Test Materials:}

\section{Expansive Soil}

Based on the plasticity characteristics, the soil may be classified as $\mathrm{CH}$. Based on its free swell index(FSI), it may be characterized as clay with high swelling potential.

\section{Granular Material}

The granular material used for the granular pile is a blend of $20 \%$ stone chips and $80 \%$ coarse sand. The size of the stone chips varied from $6 \mathrm{~mm}$ to $10 \mathrm{~mm}$. Coarse sand size varied between $2.4 \mathrm{~mm}$ and $4.75 \mathrm{~mm}$. The granular piles were compacted to a relative density of $70 \%$. 
Model tests conducted in the laboratory revealed that hurl and swell potential are immensely diminished by the establishment of granular anchor pile. The \% decrease was around 90 to 95 . It has additionally been watched that the quality attributes of the dirt expanded with the granular heap stay demonstrated a vast change in bearing capacity.

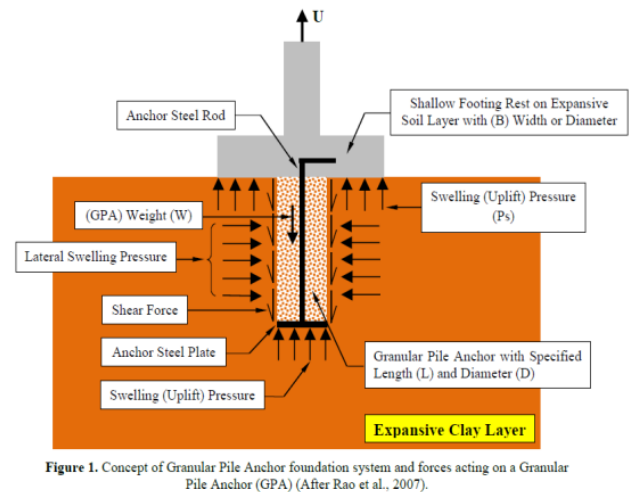

Fig 1

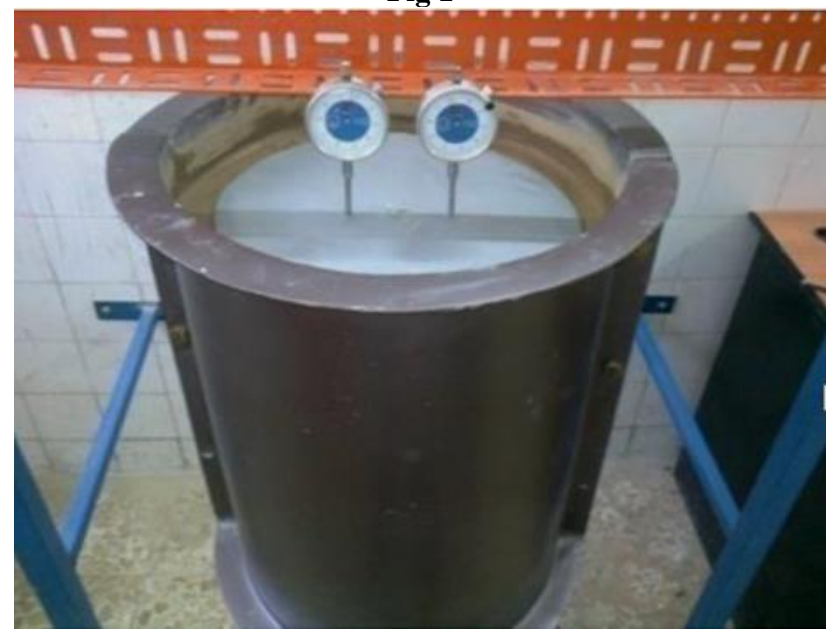

Fig.2 Plate of (GPA-Foundation system) under the heave

Field behavior of granular anchor pile anchors in expansive soils $(1,2)$ in situ tests performed and emphasized that the rate of development of final heave increased and reinforcing the expansive clay beds with this granular anchor pile increases the uplift load with increases length to diameter ratio. The granular pile anchor under the effect a group of five GPA resulted in increased uplift load in comparison of that of the single pile anchor. Based the field study of granular anchor pile foundation in expansive soils observed that heave of expansive clays can be reduced and load carrying capacity of these soil increases, because of frictional force due to shear resistance on the cylindrical surface of the granular pile.

\section{Conclusion}

Emphasis granular anchor pile foundations in expansive soils concluded that this method are used as foundation practice in expansive soils for lightly loaded structures instead of other practices in expansive soil and also it is cost effective method rather than under reamed pile foundations.

\section{References}

[1] Phanikumar BR, Sharma RS, Srirama Rao AS and Madhav (2004) "Granular pile-anchor foundation GPAF system for improving the engineering behaviour of expansive clay beds", Geotech.Test. J., 273, 279-287.

[2] Rao AS, Phanikumar BR, Babu RD and Suresh K (2007) "Pullout Behavior of Granular Pile Anchors in Expansive Clay Beds In-situ", Journal of Geotechnical and Geoenvironmental Engineering, ASCE, Vol. (133), No. (5): 531-538.
[3] Ibrahim SF, Aljorany AN and Aladly AI (2014) " Heave Behavior of Granular Pile Anchor-Foundation (GPA-Foundation) System in Expansive Soil”, J. Civil Eng. Urban, 4 (3): 213-222. 